\title{
Lignocellulose resources for the Myrothecium roridum laccase production and their integrated application for dyes removal
}

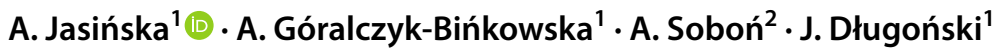

Received: 14 December 2018 / Revised: 30 January 2019 / Accepted: 18 February 2019 / Published online: 2 March 2019

(c) The Author(s) 2019

\begin{abstract}
In this study, the extracts of lignocellulosic materials such as sawdust, hay, and rapeseed press cake were used as medium for the production of laccase of the non-ligninolytic fungus Myrothecium roridum. Media prepared from hay extract and rapeseed press cake extract contributed to the highest quantity of the enzyme produced (ranging from 465 to $728 \mathrm{U} / \mathrm{L}$ after $24 \mathrm{~h}$ of cultivation). It could have resulted from the high content of reducing sugars and phenolic compounds such as gallic or ferulic acid identified in media by liquid chromatography coupled with tandem mass spectrometry. The enzyme was found to be stable in the $\mathrm{pH}$ ranging from 2 to 8 and decolorized up to $90 \%$ of Amaranth $(400 \mathrm{mg} / \mathrm{L})$ after $24-\mathrm{h}$ incubation in the presence of a selected redox mediator. After $24 \mathrm{~h}$ of incubation, laccase almost completely (97\%) decolorized the simulated dye effluent containing several dyes, metal ions, reducing agents, and detergents. An environment-friendly approach for dyes removal by laccase immobilized together with rapeseed press cake was proposed. After 24-h incubation of a dye (acid orange 7, trypan blue, and Amaranth) with laccase-rapeseed press cake alginate beads, more than 70\% decolorization was obtained. The rate of Amaranth removal was found to be about 50\% after five successive batches. Low-cost production and high decolorization efficiency in the presence of additional compounds make $M$. roridum laccase and its newly developed immobilization technique a promising option as a green catalyst for azo dyes containing wastewater treatment.
\end{abstract}

Keywords Ligninolytic enzymes · Dyes decolorization · Filamentous fungi · Bioremediation · Immobilization

\section{Introduction}

Textile and dyeing industries play a major role in the economy of many countries, but have also become one of the serious causes of water pollution. They releases large amounts of wastewaters containing hazardous chemicals such as dyes, surfactants, suspended solids, and organic

Editorial responsibility: M. Abbaspour.

Electronic supplementary material The online version of this article (https://doi.org/10.1007/s13762-019-02290-x) contains supplementary material, which is available to authorized users.

A. Jasińska

anna.jasinska@biol.uni.lodz.pl

1 Department of Industrial Microbiology and Biotechnology, Faculty of Biology and Environmental Protection, University of Lodz, Banacha 12/16, 90-237 Lodz, Poland

2 Department of Microbial Genetics, Faculty of Biology and Environmental Protection, University of Lodz, Banacha 12/16, 90-237 Lodz, Poland matter, which cause aesthetically unacceptable coloring of water bodies and block the passage of light to the lower depths of aquatic systems, resulting in the inhibition of photosynthesis. It has an adverse effect on organisms at all levels of the trophic chain (Balarak et al. 2015). Based on their chemical structure, textile dyes have been classified into azo dyes, nitro dyes, indigo dyes, anthraquinone dyes, phthalein dyes, triphenyl dyes, nitrated dyes, etc. Azo dyes comprise about $60-70 \%$ of all synthetic colorants used worldwide (Sen et al. 2016). They find application as colorants of synthetic and natural textile fibers, plastic, leather, food, hair dyes, waxes, pharmaceuticals, inks, and paints. Their popularity and usefulness result from their stability to oxygen, light, washing, and heating processes (Jasińska et al. 2016). Nevertheless, some azo dyes have been banned for use due to toxic side effects. Although they are not always toxic by themselves, their degradation products are (e.g., aromatic amines (AA)). AA are formed as a result of chemical reduction, which causes cleavage of the $\mathrm{N}=\mathrm{N}$ bond and the production of the corresponding amines (Chung 2016). This process can occur in textiles, cosmetics, or foods that 
are colored with azo dyes when the object is exposed to sweat, saliva, or symbiotic bacteria that inhabit the human skin or the gastrointestinal tract. Azo intermediates especially containing benzidine have been linked to genotoxicity, mutagenicity, and carcinogenicity in humans as well as in animals (Nguyen and Saleh 2016). According to the European Commission Regulation (Annex XVII of the REACH regulation; No. 1907/2006) (EC 2009), azo dyes that release one of the 22 aromatic amines (e.g., benzidine, 4-chloroaniline, 2-naphthylamine, and 4,4'-oxydianiline) are prohibited in all EU Member States. However, in some countries, these dyes are still being used in industries and can be illegally exported, thus endangering human life and health.

A wide range of methods have been developed for the removal of dyes from wastewaters and decrease their impact on the environment. The main mechanisms involved in these technologies are physical dye separation, breakdown of the dyes by photocatalysis, and/or by oxidation processes or decolorization by biosorption/biodegradation (dos Santos et al. 2007; Brillas and Martínez-Huitle 2015). Application of microorganisms and their enzymes in the removal of toxic dyes from environment has gained popularity due to its safety, efficiency, and ability to transform hazardous chemicals into less toxic compounds (Jasińska et al. 2016). In particular, fungal ligninolytic enzymes such as laccase, manganese peroxidase, and lignin peroxidase, which are extracellular in nature and have relatively high stability, can be easily isolated and applied in the process of biodegradation. Laccases with low substrate specificity can catalyze the oxidation of different phenolic and non-phenolic compounds; therefore, they have found application in many industrial and environmental processes (Singh et al. 2015). They require only air as the co-substrate and release water as the by-product; therefore, they can be classified as green catalysts (Mate and Alcalde 2017). Laccases from Bacillus subtilis, B. licheniformis, Trametes trogii, Pleurotus ostreatus, Pycnoporus sangineus, Ganoderma lucidum, Cerrena unicolor have been suggested for the effective dye degradation (Kuhar et al. 2015; Campos et al. 2016; Jaszek et al. 2016; Zimbardi et al. 2016; Qiao et al. 2017; Wang et al. 2017; Bhavsar et al. 2018; Zhuo et al. 2018). However, enzymatic biodegradation has to meet several criteria in order for it to be profitable, effective, and environment-friendly. First of all, biosynthesis, isolation, and preparation of the enzyme should be fast and cheap (Osma et al. 2011). To achieve this, recently, some researchers have tested lignocellulosic wastes and by-products, such as fruits peel, cereal bran and straw, and sawdust and oilcakes as growth media for the biotechnological production of laccases, which has been found to be quite promising (Songulashvili et al. 2015; Daâssi et al. 2016; Schalchli et al. 2017). According to JRC Science for Policy Report, Bioeconomy Report 2016 (Ronzon et al. 2017), the use of lignocellulosic materials for the biosynthesis of enzymes seems to be economically justified and is in line with the concept of sustainable development goals. The use of waste products for the production of enzymes allows to manage wastes generated by various industries and significantly reduces the costs of obtaining the enzyme. Lignocellulosic materials, primarily composed of polysaccharides (cellulose and hemicellulose) and lignin, have been demonstrated to stimulate fungal growth and the production of laccase (Cavka and Jönsson 2014). They can also be utilized as adsorbents of pollutants. For example, canola residues, rice husks, rapeseed press cake (RPC), brewery grains, or plant leaves showed an excellent capability to remove contaminants, such as organic pollutants and heavy metals from aqueous solutions (Silva et al. 2004; Jasińska et al. 2013; Ashrafi et al. 2015; Balarak et al. 2015; Guerrero-Coronilla et al. 2015).

Immobilization of enzymes on lignocellulosic wastes seems to be a promising alternative for conventional supports. The use of alternative matrices could help to reduce the cost of the enzyme immobilization process and allows application on an industrial scale. Lignocellulosic materials were successfully applied for lipases, invertases, amylases and laccases immobilization (de Souza Bezerra et al. 2015). However, there are no reports showing the immobilization of laccase with the use of waste materials after the production of this enzyme. Therefore, the aim of the study was to produce the laccase of the non-ligninolytic fungus Myrothecium roridum in the eco-friendly and cost-effective approach and use it in the degradation of azo dyes. We used the extracts of a sawdust (SE), hay (HE), and rapeseed press cake extract(s) (RPCE) as the media. The media were preliminarily characterized for total proteins, phenols, and reducing sugars estimation, followed by liquid chromatography coupled with tandem mass spectrometry (LC-MS/MS)-based measurement of selected phenolic compounds. The enzyme was tested on decolorization of the azo dye Amaranth in a wide range of $\mathrm{pH}$. Redox mediators' influence on the elimination of dye was also tested. According to the assumption of zerowaste bioprocessing, RPC that remained after the preparation of the medium was successfully used for the novel costeffective immobilization of the enzyme and removal of the dyes. The entire work was carried out in the Department of Industrial Microbiology and Biotechnology, University of Lodz, Poland, from April 2017 to March 2018.

\section{Materials and methods}

\section{Chemicals}

All chemicals used in this study were of certified reagent analytical grade. The following azo dyes were used: Amaranth, acid orange 7 (AO7), Acid blue 113 (AB113), trypan 
blue (TB), and Sunset Yellow FCF (SY FCF). Dyes were purchased from Sigma-Aldrich (USA). Stock dye solutions $(50 \mathrm{mg} / \mathrm{mL}$ in water) were sterilized and stored in the dark at $4{ }^{\circ} \mathrm{C}$. In addition, 2,2-azinobis-3-ethylbenzothiazoline6-sulfonic acid (ABTS); 2,6-dimethoxyphenol (DMP); 2,2,6,6-tetramethylpiperidine 1-oxyl (TEMPO); gallic acid (GA); caffeic acid (CA); vanillin (V); $p$-hydroxybenzoic acid (HBA); and syringaldehyde (S) were purchased from SigmaAldrich (USA). The other chemicals were obtained from Idalia (Poland) and POCh (Poland). Sawdust, RPC, and hay were purchased from a local market in Lodz, Poland.

\section{Microorganism}

Filamentous fungus $M$. roridum IM 6482 was isolated from soil samples collected around a textile dyeing factory (Zgierz, Poland). The strain was identified by molecular techniques and preserved in the strain collection of the Department of Industrial Microbiology and Biotechnology, University of Lodz (Poland). The strain was regularly subcultured on ZT slants and maintained at $4{ }^{\circ} \mathrm{C}$. Laccase production was proven in both static and submerged cultures by using ABTS and syringaldazine as the substrates (Jasińska et al. 2012).

\section{Media preparation}

In this study, sawdust $(5 \times 5 \times 2 \mathrm{~mm}), \operatorname{RPC}(2 \times 2 \times 2 \mathrm{~mm})$, and hay $(5 \times 5 \times 2 \mathrm{~mm})$ were used as the substrates for the production of laccase by $M$. roridum under submerged conditions. Hot water extracts of the media were prepared according to a previous study (Atlas 2010). $\mathrm{pH}$ was adjusted to 6.8. Media were used as pure extracts with or without the supplementation of $0.75 \%(\mathrm{w} / \mathrm{v})$ of glucose and $0.3 \%(\mathrm{w} / \mathrm{v})$ of yeast extract. Next, the media were supplemented with $1 \mathrm{mM} \mathrm{CuSO}_{4}$ as an inducer of laccase. The extracts were analyzed for the content of total proteins, reducing sugars, and phenols.

Protein concentration was determined using the BCA method (according to the Pierce ${ }^{\mathrm{TM}}$ BCA Protein Assay Kit protocol).

Reducing sugars were determined according to the method described by Miller (1959) with some modifications. Specifically, the diluted samples and 3,5-dinitrosalicylic acid (DNS) solvent (prepared by dissolving $1 \mathrm{~g}$ of DNS in $20 \mathrm{~mL}$ of $2 \mathrm{M} \mathrm{NaOH}$ and the volume adjusted to $100 \mathrm{~mL}$ with citrate-phosphate buffer $\mathrm{pH} 8.0$ ) were thoroughly mixed and reacted in boiling water bath for $5 \mathrm{~min}$. The absorbance of the sample was measured at $540 \mathrm{~nm}$, and the amount of sugar was determined based on the absorbance of the glucose as the standard.

Determination of phenolic compounds was performed by the modified Folin-Ciocalteu method (Singleton et al. 1965).
Briefly, $188 \mu \mathrm{L}$ of deionized water, $12 \mu \mathrm{L}$ of Folin-Ciocalteu reagent, and $30 \mu \mathrm{L}$ of $\mathrm{Na}_{2} \mathrm{CO}_{3}(200 \mathrm{~g} / \mathrm{L})$ were added to the sample $(20 \mu \mathrm{L})$. Then, the samples were incubated in the dark at room temperature for $1 \mathrm{~h}$. Next, deionized water $(50 \mu \mathrm{L})$ was added and the absorbance was measured at $765 \mathrm{~nm}$. Simultaneously, a standard curve was prepared using GA solutions with the following concentrations: 0.00 , $0.05,0.10,0.25,0.50,0.75$, and $1.00 \mathrm{mg} / \mathrm{L}$.

LC-MS/MS was performed to determine the phenolic contents in extracts using Agilent 1200 chromatograph (Agilent, USA) coupled with QTRAP 3200 mass spectrometer (SCIEX, USA). Chromatographic separation was performed on a Synergi Hydro-RP column $(2 \times 150 \mathrm{~mm}, 4 \mu \mathrm{m})$ (Phenomenex, Germany) according to parameters described in Table S1. The flow rate was set to $600 \mu \mathrm{L} / \mathrm{min}$ at $50{ }^{\circ} \mathrm{C}$, and the injection volume was set to $10 \mu \mathrm{L}$. The applied eluents were water (A) and acetonitrile (B), both supplemented with $0.1 \%$ formic acid. The 10 -min separation time was started from 5\% B for 1 min followed by a linear increase to $95 \%$ $\mathrm{B}$ for $5 \mathrm{~min}$ and held for $2 \mathrm{~min}$ and then decreased to $5 \% \mathrm{~B}$ and held for $2 \mathrm{~min}$. The MS parameters (in negative ionization mode) were as follows: IS: $-4500 \mathrm{~V}$, Cur: 25 , GS1: 50, GS2: 60 , temperature: $500{ }^{\circ} \mathrm{C}$. Ionization polarity, optimal declustering potential (DP), product ion, and collision energy (CE) for all compounds were manually tuned using standard solutions as presented in Table S1.

\section{Laccase production and purification}

Laccase was produced by submerged cultures. To prepare the inoculum, $7 \mathrm{~mL}$ of the WHI medium containing peptone $(5 \mathrm{~g} / \mathrm{L})$, yeast extract $(5 \mathrm{~g} / \mathrm{L}), \mathrm{KH}_{2} \mathrm{PO}_{4}(5 \mathrm{~g} / \mathrm{L})$, glucose $(2 \%(\mathrm{v} / \mathrm{v}))$, and soybean oil $(0.025 \%(\mathrm{v} / \mathrm{v}))$ was added to a fully sporulated culture slant. A preculture was prepared by using spore suspension of approximately $5 \times 10^{9}$ spores $/ \mathrm{mL}$, which was incubated at $28^{\circ} \mathrm{C}$ with shaking at $140 \mathrm{rpm}$ for $24 \mathrm{~h}$. These precultures were transferred to a fresh medium $(10 \%, \mathrm{v} / \mathrm{v})$ and incubated for another $24 \mathrm{~h}$. Cultures of $M$. roridum IM 6482 prepared in 1-L Erlenmeyer flasks containing $270 \mathrm{~mL}$ of each test medium prepared according to "Media preparation" section were inoculated with $30 \mathrm{~mL}$ of a homogenous preculture. Cultures were incubated with shaking $(150 \mathrm{rpm})$ at $28{ }^{\circ} \mathrm{C}$. At appropriate time intervals, the cultures were centrifuged $(3500 \times g, 15 \mathrm{~min})$. Fungal biomass was washed with distilled water and dried overnight in an air oven at $80^{\circ} \mathrm{C}$. Laccase activity in the extracellular fluid was determined spectrophotometrically according to the method described earlier with ABTS as a substrate (Eggert et al. 1996). The obtained filtrate with the highest laccase activity was used for the protein precipitation and purification according to the method described by Jasińska et al. (2018). 


\section{Effects of pH on laccase activity and stability}

Optimum $\mathrm{pH}$ values for the laccase activity were determined at a pH range of 2.2-8.0 using Mcllvaine buffer at room temperature and ABTS as the substrate. For $\mathrm{pH}$ stability testing, the enzyme was incubated at $\mathrm{pH}$ values ranging from 2.2 to 8.0 in Mcllvaine buffer for $4 \mathrm{~h}$ at room temperature. Then, the residual laccase activity was determined under standard reaction conditions with ABTS as the substrate.

\section{Decolorization experiment}

The decolorization experiment was performed at room temperature. The course of decolorization was studied by measuring the absorbance at the appropriate wavelength $\left(\lambda_{\max }\right)$ for a given dye (AO7, $485 \mathrm{~nm}$; AB113, $556 \mathrm{~nm}$; Amaranth, $521 \mathrm{~nm}$; TB, $607 \mathrm{~nm}$; and SY FCF, $482 \mathrm{~nm}$ ). The reaction mixture contained a dye prepared at a specified concentration $(50,100,200$, or $400 \mathrm{mg} / \mathrm{L})$ in a buffer of the appropriate $\mathrm{pH}(2.2,3,4,5,6,7$, or 8$)$. The effect of reaction mediators such as ABTS, TEMPO, DMP, GA, CA, and V $(100 \mu \mathrm{M})$ was analyzed. The decolorization of Amaranth was also evaluated from simulated dye effluent (SDE) containing additional compounds: $\mathrm{Zn}\left(\mathrm{CH}_{3} \mathrm{COOH}\right)_{2} \times 2 \mathrm{H}_{2} \mathrm{O}$; $\mathrm{Co}\left(\mathrm{CH}_{3} \mathrm{COOH}\right)_{2} \times 4 \mathrm{H}_{2} \mathrm{O} ; \mathrm{Cd}\left(\mathrm{CH}_{3} \mathrm{COOH}\right)_{2} \times 2 \mathrm{H}_{2} \mathrm{O}$; and $\mathrm{NaCl}$ (at concentration $0.1 \mathrm{mM}$ ); Tween 80; SDS; urea; and EDTA (at concentration $0.1 \%$ ) and the mixture of dyes AB113; AO7; SY FCF; Amaranth; and TB (each at concentration $50 \mathrm{mg} / \mathrm{L}$ ). The decolorization was expressed as a percentage of color loss with reference to the control sample without enzyme. All measurements were repeated thrice, and the average values were used for all calculations.

\section{Immobilization and reusability experiment}

For immobilization of laccase, $2 \mathrm{~g}$ of sodium alginate was prepared by dissolving in $10 \mathrm{~mL}$ water. To the sodium alginate solution, an equivalent amount of enzyme extract (25 IU), RPC (10 g/L), or both of them were added under continuous stirring. Then, the mixture was dropped into chilled $\mathrm{CuSO}_{4} \times 5 \mathrm{H}_{2} \mathrm{O}$ solution $(150 \mathrm{mM})$, and the resulting beads were allowed to harden in the same solution for $2 \mathrm{~h}$ under mild agitation. After this, the beads were collected and washed several times by using deionized water, until there was no detectable laccase activity in the solution. Then, these beads were used in the decolorization experiment according to method described in "Decolorization experiment" section. The reusability of the immobilized laccase for the decolorization of dyes was tested for up to five successive batches of 24-h incubation each. After every decolorization cycle, alginate beads were filtered and washed thrice with deionized water. The cleaned beads were reused for the next decolorization cycle.

\section{Results and discussion}

\section{Fungal growth and laccase production on waste materials}

Biotechnological applications require large amounts of low-cost enzymes. Therefore, one of the appropriate approaches is to utilize the waste materials or cheap agricultural by-products for the preparation of growth medium. During media preparation as well as during solid-state fermentation, some soluble carbohydrates and inducers are released, which ensure efficient production of enzymes (Singhaniaa et al. 2009). In this study, different lignocellulosic materials $(5 \% \mathrm{w} / \mathrm{v})$ were used to prepare the medium (according to method described in "Media preparation" section). The type of waste material used to prepare the medium strongly influenced the growth of $M$. roridum and laccase production (Fig. 1). Growth of the fungus was similar in medium prepared from HE or RPCE. Dry weight of mycelium obtained after 24- and 48-h cultivation in the aforementioned media reached 6.93 and $6.68 \mathrm{mg} / \mathrm{mL}$, and the activity of the enzyme in their supernatants reached 566 and $728 \mathrm{U} / \mathrm{L}$, respectively, which was found to be almost 2 and 3 times higher than the activity assessed in SE medium. The better growth and laccase production in RPCE and HE media might be due to the availability of some nutrients that are necessary for the growth of the fungus. The initial characterization of media showed the highest content of reducing sugars $(1490 \mu \mathrm{g} / \mathrm{mL})$ in HE medium. Phenolic acids, which are natural products of lignin degradation, can affect the activity of laccase. Previously, many studies have demonstrated that a large proportion of phenolic compounds remain in the rapeseed meal after oil press (Szydłowska-Czerniak and Łaszewska 2015; Vuorela et al. 2004). In this study, the highest concentration of phenolic compounds was detected in RPCE medium $(820 \mu \mathrm{g} / \mathrm{mL})$. Rapeseed and grass hay are rich in phenolics, the major secondary metabolites obtained from plants (Yang et al. 2014). LC-MS/MS analysis revealed the presence of FA and HBA as well as V in all the tested media (Table 1). In addition, HE medium contained GA $(59.4 \mathrm{ng} / \mathrm{mL})$, which was not present in other media. Figure 2 presents the chromatograms of $\mathrm{V}$ obtained for standard, HE, RPCE, and SE. All extracts contained compounds with retention times similar to standards, which suggest the need to broaden the range of phenolic substances to be tested. The inductive effect of GA, HBA, CA, FA, $p$-coumaric, and sinapic acid on laccase has been reported earlier (Wang et al. 2014; Adekunle et al. 2017). The effect of supplementation of medium with RPC on the production of laccase, chitinase, and $\beta$-glucosidase by white rot fungus Cerrena unicolor has been previously described 
Fig. 1 Growth $(\mathrm{mg} / \mathrm{mL})$ and laccase activity (U/L) during the cultivation of $M$. roridum in medium containing HE (a), RPCE (b), or SE (c) supplemented with glucose and yeast extract (Glc + YE) or without supplementation
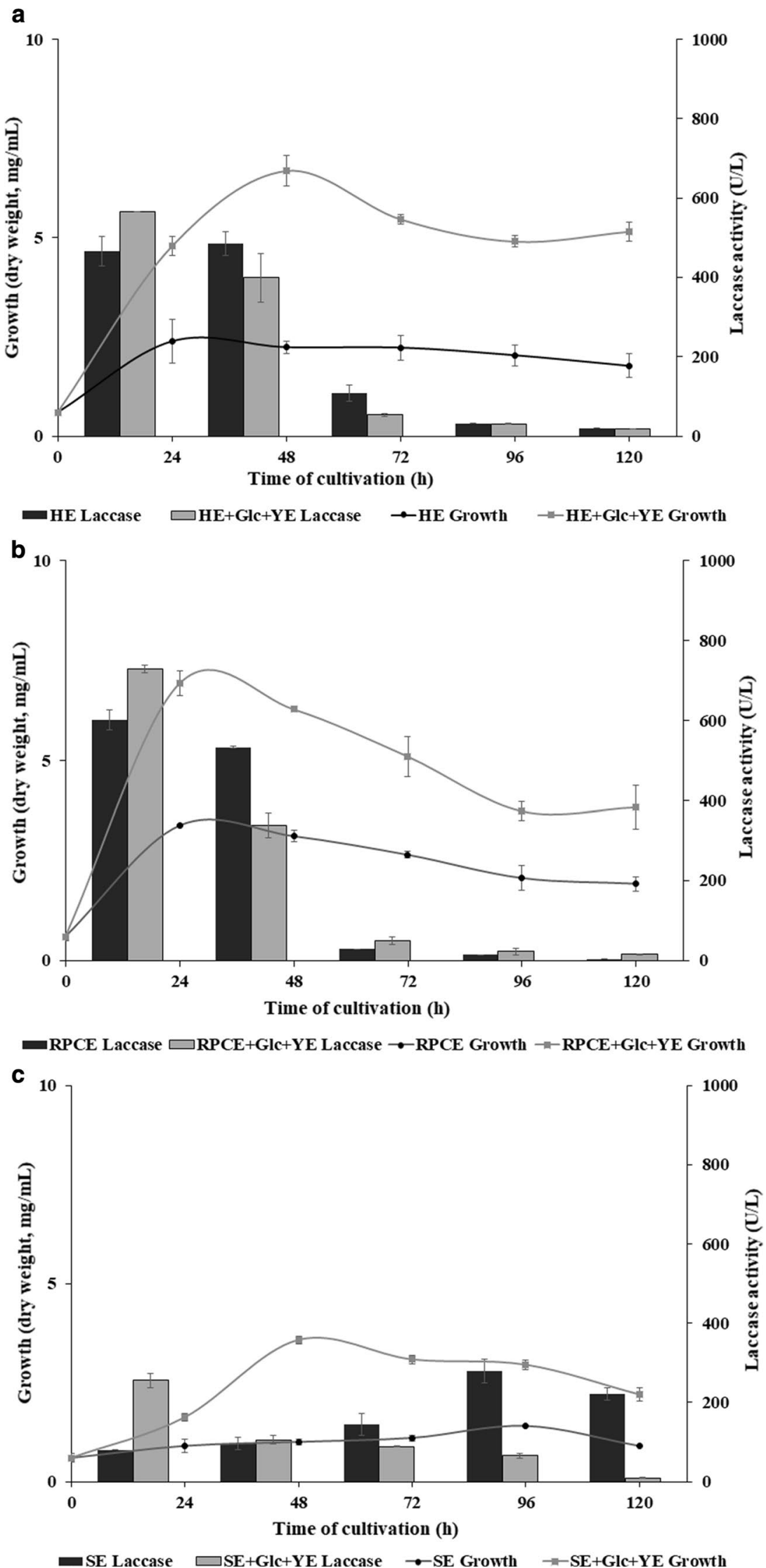
Table 1 Initial characterization of water extracts of hay, rapeseed press cake, and sawdust used in this study as a media for laccase production

\begin{tabular}{llll}
\hline Compound & \multicolumn{3}{l}{ Concentration in medium $(\mu \mathrm{g} / \mathrm{mL})$} \\
\cline { 2 - 4 } & HE & RPCE & SE \\
\hline Total protein & 2260.0 & 2850.0 & 770.0 \\
Reducing sugars & 1490.0 & 1170.0 & 250.0 \\
Total phenols & 440.0 & 820.0 & 50.0 \\
GA & 0.0594 & ND & ND \\
FA & 0.3624 & 0.4168 & $<0.005$ \\
HBA & 0.2055 & 0.1858 & $<0.005$ \\
S & ND & $<0.005$ & ND \\
V & 0.0742 & $<0.005$ & 0.2051 \\
\hline
\end{tabular}

by Jaszek et al. (2016). The addition of RPC (3.5\% w/v) distinctly stimulated the activities of enzymes. However, this is the first study reporting on HE and RPCE for the preparation of media. High content of reducing sugars and phenolic compounds in HE and RPCE makes them as an innovative, low-cost, and easily available media for the production of laccase.

\section{Application of $M$. roridum laccase in the decolorization of Amaranth}

Laccase decolorization potential was investigated with the use of Amaranth as a model azo dye. Amaranth (C.I. Name Acid red 24) has been widely used as a colorant of synthetic fiber, leather, paper, and phenol-formaldehyde resin in industries. The dye is also used in the food industry to color various food products. However, it is reported to be potentially cytotoxic and genotoxic. It can also cause allergic and asthmatic reactions, in some sensitive people, when it comes in contact with certain drugs such as aspirin (Mpountoukas et al. 2010; Zhang and Ma 2013; Basu and Kumar 2015). Since 1976, Amaranth has been banned by the United States Food and Drug Administration (USFDA) as a suspected carcinogen. However, it is still being used illegally in some countries. Therefore, considering the potential adverse effects of Amaranth on human health, there is an
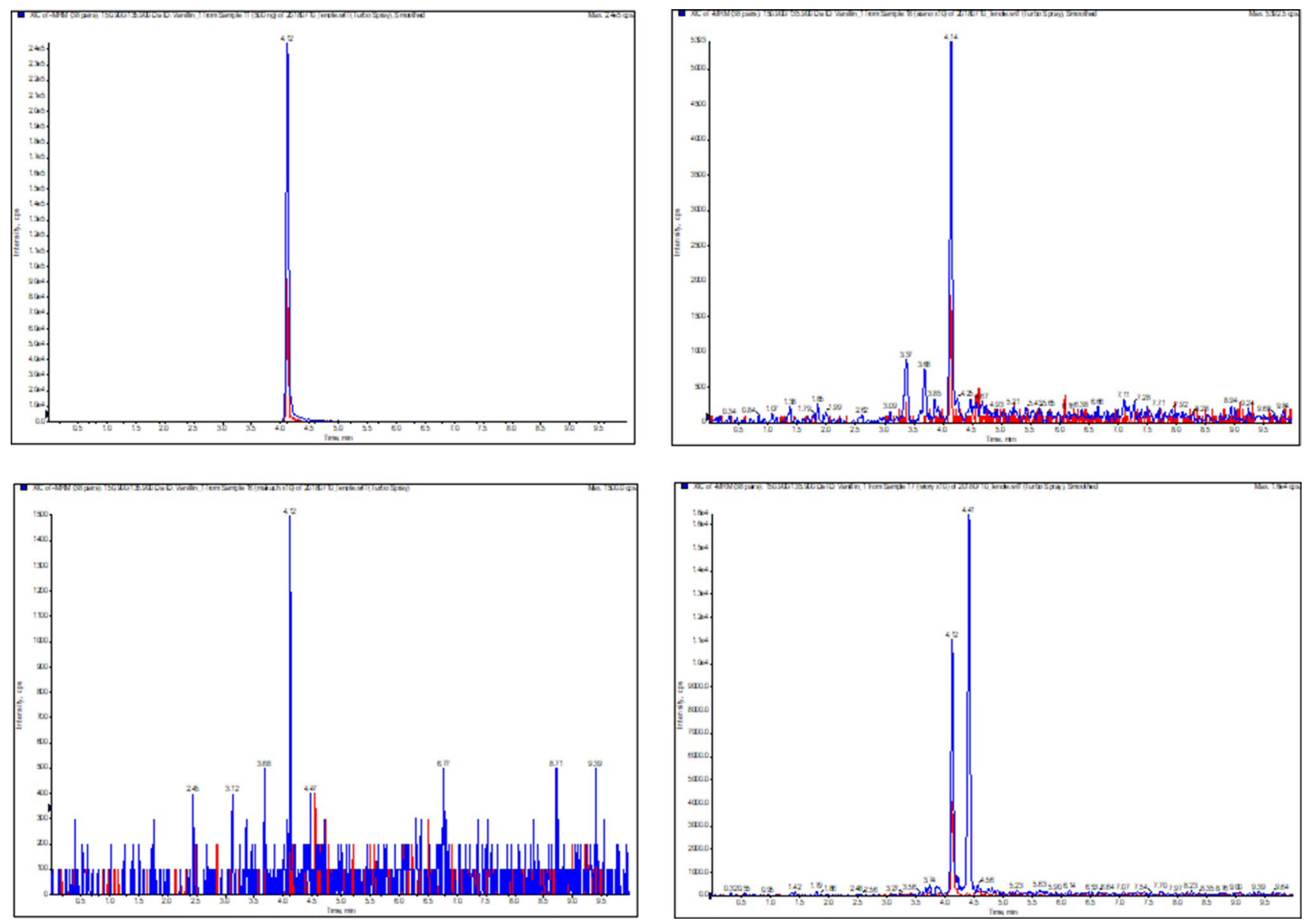

Fig. 2 HPLC chromatograms of vanillin (V) obtained for standard solution (a), HE (b), RPCE (c), or SE (d) 
urgent need to regulate the consumption of this synthetic colorant as well as eliminate the residues of this dye from the environment. Degradation and decolorization of azo dyes by fungal laccases have gained more attention recently because of their environment-friendly and inexpensive nature. In our study, after 24-h cultivation of M. roridum in RPCE medium, laccase was precipitated and prepared as previously described (Jasińska et al. 2018). The purified laccase was tested for decolorization of Amaranth at different operational conditions.

\section{Influence of pH on laccase activity, stability, and Amaranth decolorization}

First, the influence of $\mathrm{pH}$ on laccase activity and dye decolorization in the $\mathrm{pH}$ range $2.2-8.0$ at room temperature was examined. The results are presented in Fig. 3. The optimum $\mathrm{pH}$ of fungal laccase reported in the literature for the substrate ABTS is in the range of 3.0-6.0 (Fang et al. 2015). In this study, the enzyme was active in solutions with $\mathrm{pH}$ ranging from 2.2 to 8.0 , whereas optimum $\mathrm{pH}$ for laccase activity was found to be at $\mathrm{pH} 4.0$ which was found to be similar to what has been reported previously (Koschorreck et al. 2008; Yang et al. 2015; Zhuo et al. 2018). This agrees with our results obtained in the decolorization experiment, where Amaranth was most effectively decolorized within the first hour of incubation in solutions with $\mathrm{pH} 2-4$. Extending the time of incubation did not increase the elimination of the dye from solutions with $\mathrm{pH} 2-4$, but allowed to obtain high removal of the dye from solutions with neutral and slightly alkaline $\mathrm{pH}(7-8)$. The highest decolorization of the dye $(91.56 \%)$ was detected after 24-h incubation with laccase in solution with $\mathrm{pH} 8$. It is compatible with the results of enzyme stability. Laccase was found to be most stable after 4-h incubation in solutions

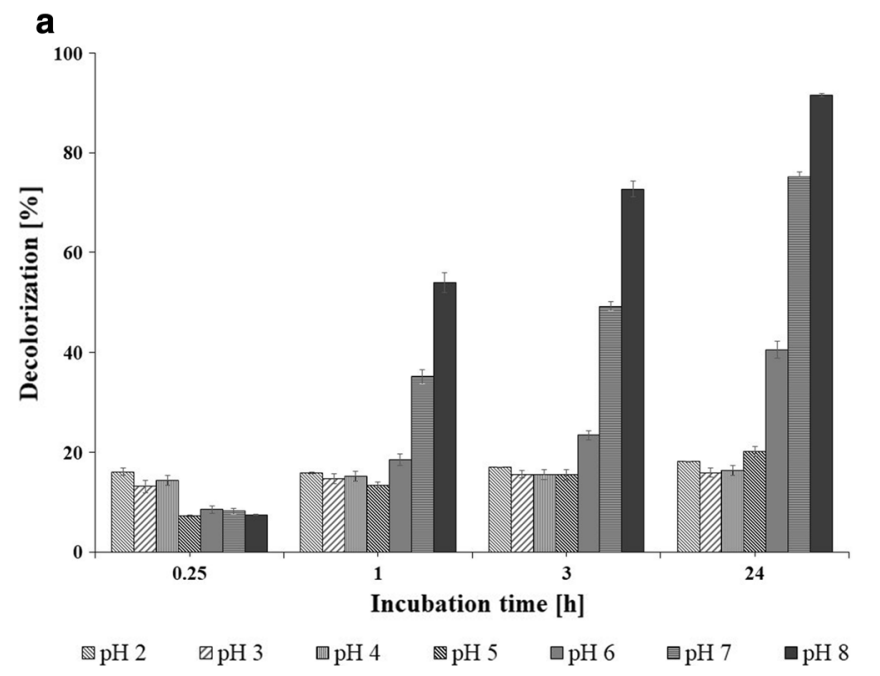

with $\mathrm{pH} 8$. However, it demonstrated high stability over $\mathrm{pH}$ ranging from 5 to 8 , retaining over $80 \%$ of its initial activity after 4-h incubation at relevant $\mathrm{pH}$. Most textile effluents are characterized by their alkaline $\mathrm{pH}$, where most fungal laccases can lose their activities. This indicates that $M$. roridum laccase is a good candidate for basic and applied research with potentials for various industrial and biotechnological applications employing varying levels of $\mathrm{pH}$.

\section{Laccase-mediator system for decolorization improvement}

To improve the degree of decolorization of Amaranth, the substrate was treated with $M$. roridum laccase in combination with one of the mediators ABTS, DMP, TEMPO, V, $\mathrm{GA}$, or CA. According to the results, no significant effect on the decolorization was observed when Amaranth was at

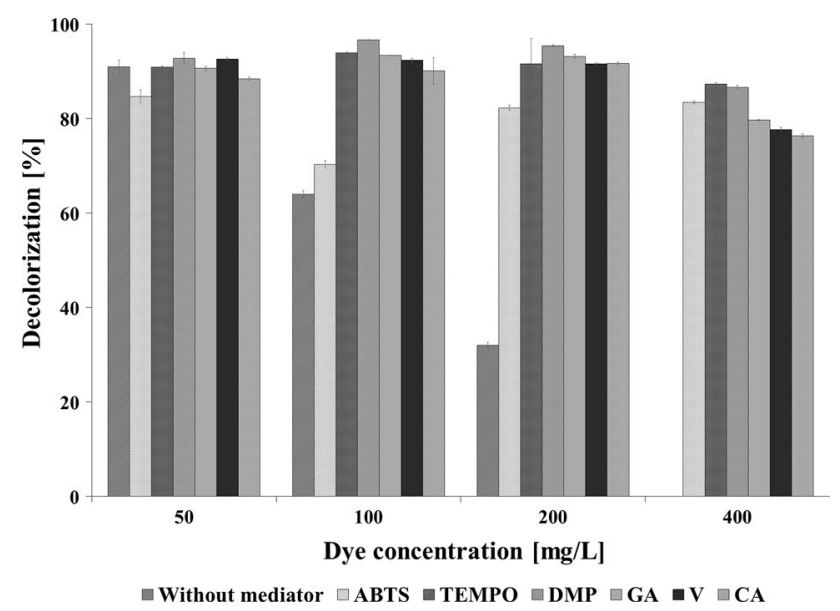

Fig. 4 Effect of redox mediators $(100 \mu \mathrm{M})$ on Amaranth (50$400 \mathrm{mg} / \mathrm{L})$ decolorization by $M$. roridum laccase $(1 \mathrm{U} / \mathrm{mL})$

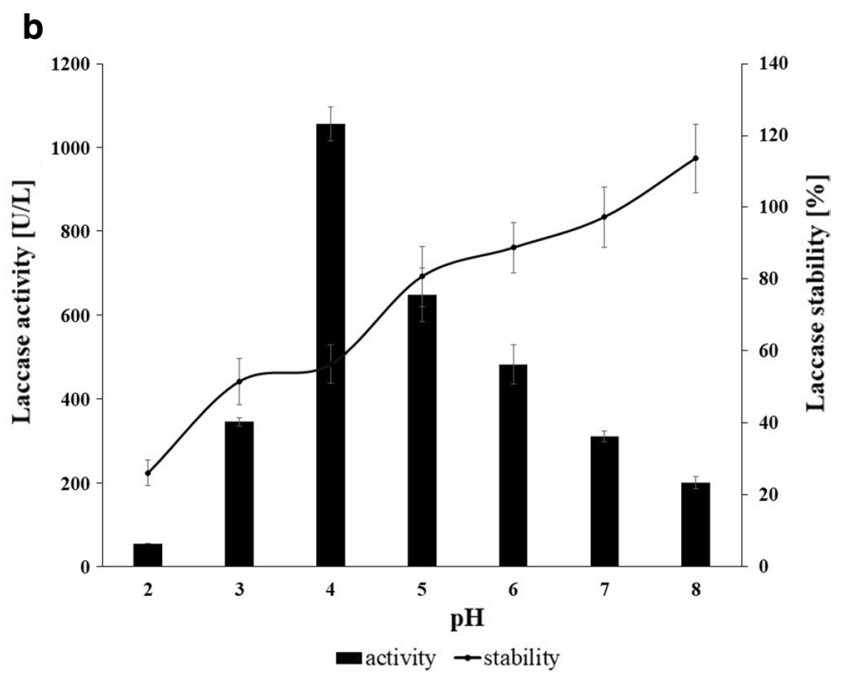

Fig. 3 Influence of $\mathrm{pH}$ on decolorization of Amaranth $(50 \mathrm{mg} / \mathrm{L})$ by $M$. roridum laccase $(1 \mathrm{U} / \mathrm{mL})(\mathbf{a})$ and laccase activity and stability $(\mathbf{b})$ 
$50 \mathrm{mg} / \mathrm{L}$ (Fig. 4). However, all tested mediators increased the level of decolorization of Amaranth at concentrations more than $100 \mathrm{mg} / \mathrm{L}$. After $4 \mathrm{~h}$ of decolorization in the mixture without mediators, Amaranth at a concentration as high as $400 \mathrm{mg} / \mathrm{L}$ was not found to be decolorized, whereas the addition of mediators resulted in the decolorization of the dye ranging from 76 to $87 \%$. Because of their toxicity, most of the previously reported microbial decolorization systems cannot remove high concentration of dyes. Thus, primarily physicochemical processes are applied in the wastewater treatment. However, the application of mediators that are naturally present in the environment and have no toxic effects seems to be a promising alternative for the treatment of wastewater containing high concentration of dyes.

\section{SDE decolorization}

Effluents from the dyeing industries are characterized by the presence of low contents of metal and suspended solids; high chemical oxygen demand (COD); chlorinated organic compounds; surfactants; and intense color (Yaseen and Scholz 2018). Thus, to initially evaluate the possibility of using laccase from $M$. roridum for the treatment of real wastewater, we examined the decolorization of SDE (Fig. 5). When compared to a single dye solution, decolorization of SDE was found to be faster and after just 15 min of incubation with M. roridum laccase decolorization of SDE was found to be twice greater than the decolorization of a single dye. This result may be due to the effect of induction by metal ions on the activity of laccases, for example, as a result of avertable conformational changes. Notably, the

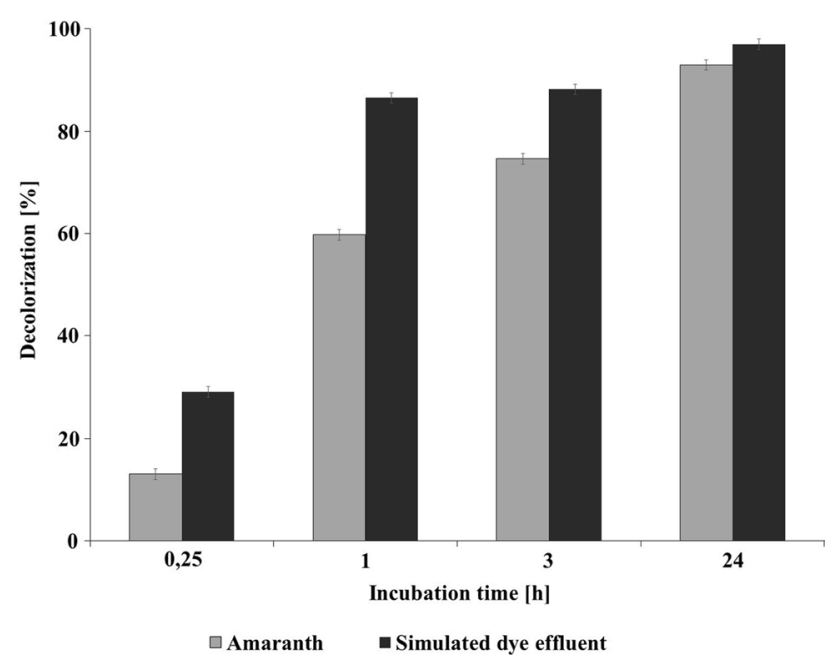

Fig. 5 Decolorization of Amaranth (50 mg/L) from single dye solutions or from SDE by $M$. roridum laccase $(1 \mathrm{U} / \mathrm{mL})$ within $24 \mathrm{~h}$ in the presence of $\mathrm{V}(100 \mu \mathrm{M})$ enhanced activity of laccase by copper ions may be due to the incorporation of copper ions into the type-2 copperbinding sites. Similarly, numerous studies have also indicated that the addition of surfactants, primarily nonionic, such as Triton X-100, rhamnolipid, and Tween 80, might increase the removal of some xenobiotics by laccases by the protection of the enzyme, by changing the activity center, and by enhancing the solubility of xenobiotics. Ionic surfactants cause adverse effects, which impair the removal processes (Liu et al. 2012a, b).

\section{Preliminary study on zero-waste approach for azo dyes removal}

Previous work demonstrated that oilseed press cakes have the ability to absorb pollutants. Rapeseed, almond, sunflower, olive press cakes have been described as efficient sorbent materials for azo dye removal (Karagöz et al. 2008; Jasińska et al. 2013). Laccases have been immobilized on various types of supports, such as silica, activated carbon, chitosan, and alginate. Immobilization of enzymes on agroindustrial residues (e.g., coconut fiber, granular waste from a brewery, and rice straw) also has great potential because of its physical characteristics, chemical composition, and low-cost nature. To date, no research about the laccase immobilization on spent RPC has been reported. Therefore, considering the advantages of RPC as biosorbent and catalytic properties of laccase, a zero-waste approach in the removal of azo dyes was proposed in this study. It involved copper alginate immobilization of laccase together with RPC remained after the preparation of the growth medium for enzyme production. Decolorization of five azo dyes (AO7, Amaranth, AB113, SY FCF, and TB) was investigated using immobilized RPC, immobilized laccase, or immobilized mixture of both. After 24-h incubation, all the tested dyes were found to be decolorized at different extents (Fig. 6a). The highest rate of decolorization was found in solutions containing TB (83\%), Amaranth (74\%), and $\mathrm{AO} 7(81 \%)$ using immobilized mixture of laccase and RPC. Decolorization was found to be higher on $17-29 \%$ than in the presence of immobilized RPC and about 2-6 higher than when laccase was immobilized alone. To date, mainly physicochemical processes as well as adsorption using various adsorbents have been used to remove these dyes from aqueous solutions. Efficient elimination of TB, Amaranth, and AO7 was obtained by using some natural adsorbents such spent brewery grains (Silva et al. 2004) and plant leaves (Guerrero-Coronilla et al. 2015). Jung et al. (2016) applied activated carbon powder derived from spent coffee grounds into calcium alginate beads for the removal of AO7. After 24-h incubation, almost complete removal of the dye was achieved. However, this is the first study 

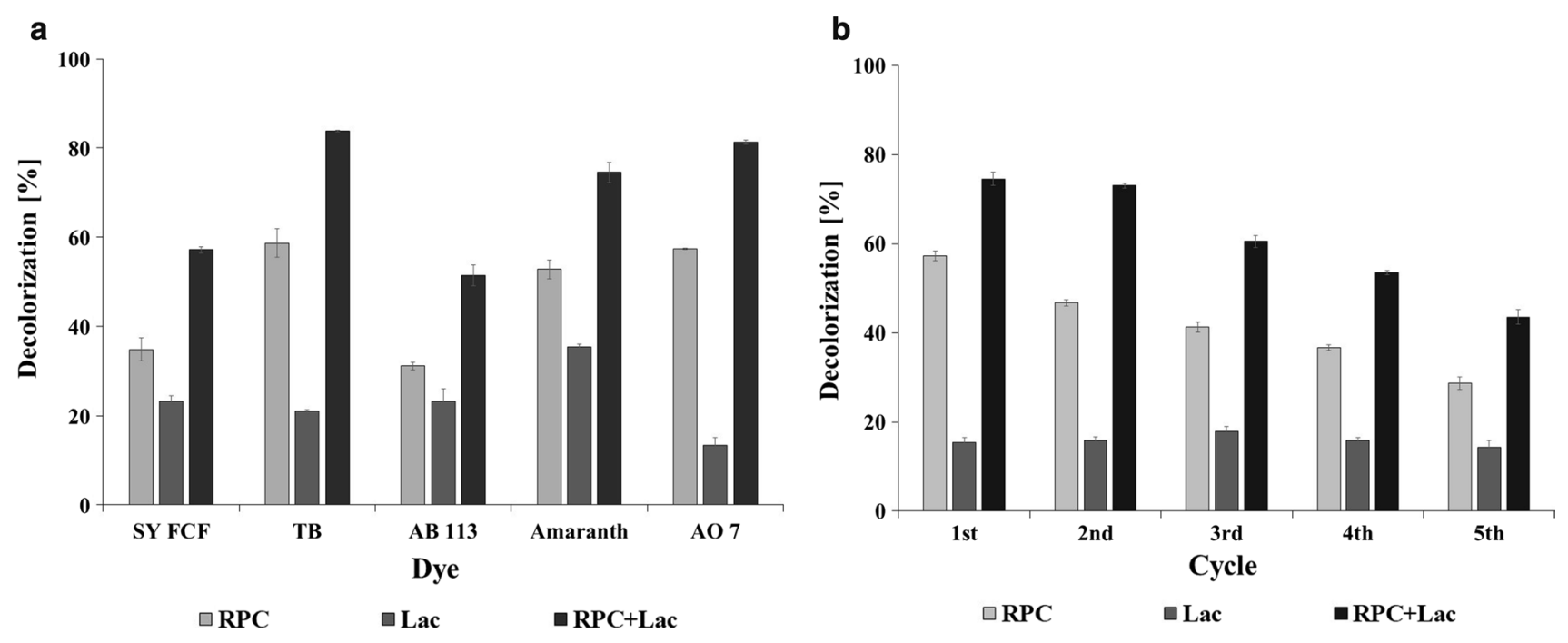

Fig. 6 Application (a) and reusability (b) of RPC, laccase, or RPC + laccase immobilized on copper alginate beads for the removal of various azo dyes

reporting the simultaneous immobilization of biosorbent and laccase for more efficient removal of dye.

As shown in Fig. 6b, the rate of removal of Amaranth by laccase immobilized with RPC even after five successive batches of 24-h incubation was found to be about 50\%. Rate of Amaranth decolorization decreased clearly for immobilized RPC, whereas immobilized laccase decolorized the dye to the same extent. The decrease in the removal efficiency may be due to the reduction in the number of binding sites for the dye molecules, not due to the loss of the activity of laccase. Reusability of immobilized enzyme in the biodegradation process shows that the most important aspect for industrial application is being cost-effective, since it decreases the overall cost of the process.

\section{Conclusion}

Lignocellulosic materials such as sawdust, hay, and RPC have low economic value; therefore, their use as substrate for laccase production can significantly reduce the cost of the procurement of the enzyme. In this study, the use of water extracts of sawdust, hay, and RPC for the production of laccase from the fungus $M$. roridum was reported for the first time. The highest enzyme production was noted in HE and RPCE media and was correlated with the high concentration of reducing sugars and several phenolic compounds. Laccase occurred to be stable in the $\mathrm{pH}$ ranging from 2 to 8 and is able to decolorize the azo dye Amaranth $(50 \mathrm{mg} / \mathrm{L})$. Application of redox mediators allowed for $90 \%$ decolorization of up to $400 \mathrm{mg} / \mathrm{L}$ of Amaranth after $24 \mathrm{~h}$ of incubation. The enzyme decolorized the SDE containing several azo dyes, metal ions, reducing agents, and detergents. An environment-friendly approach involving copper alginate immobilization of laccase together with RPC remaining after the preparation of the medium for enzyme production was applied for azo dyes removal. After $24 \mathrm{~h}$ of incubation in dye solution, laccase/RPC alginate beads decolorized the AO 7, $\mathrm{TB}$, and Amaranth by more than $70 \%$. The removal rate of Amaranth by laccase immobilized with RPC was still about $50 \%$ after five successive batches of $24 \mathrm{~h}$ each. Due to the $\mathrm{pH}$ stability, high efficiency of decolorization of single azo dyes, as well as SDE, laccase seems to be an attractive candidate for different environmental purposes. Additionally, an innovative approach involving copper alginate immobilization of laccase and RPC remaining after the preparation of growth medium for the production of enzyme is a promising option as an eco-friendly catalyst for dyestuff treatment.

Acknowledgements This work is a result of Project No. UMO 2013/11/D/NZ9/02776 financed by the National Science Center of Poland.

Open Access This article is distributed under the terms of the Creative Commons Attribution 4.0 International License (http://creativeco mmons.org/licenses/by/4.0/), which permits unrestricted use, distribution, and reproduction in any medium, provided you give appropriate credit to the original author(s) and the source, provide a link to the Creative Commons license, and indicate if changes were made.

\section{References}

Adekunle AE, Zhang C, Guo C, Liu CZ (2017) Laccase production from Trametes versicolor in solid-state fermentation of 
steam-exploded pretreated cornstalk. Waste Biomass Valorization 8:153-159

Ashrafi SD, Kamani H, Jaafari J, Mahvi AH (2015) Experimental design and response surface modeling for optimization of fluoroquinolone removal from aqueous solution by $\mathrm{NaOH}$-modified rice husk. Desalin Water Treat 57:16456-16465

Atlas RM (2010) Handbook of microbiological media. ASM Press, Washington, DC

Balarak D, Jaafari J, Hassani G, Mahdavi Y, Tyagi I, Agarwal S, Gupta VK (2015) The use of low-cost adsorbent (Canola residues) for the adsorption of methylene blue from aqueous solution: isotherm, kinetic and thermodynamic studies. Colloid Interf Sci Commun 7:16-19

Basu A, Kumar GS (2015) Interaction of toxic azo dyes with heme protein: biophysical insights into the binding aspect of the food additive amaranth with human haemoglobin. J Hazard Mater 289:204-209

Bhavsar S, Dudhagara P, Tank P (2018) R software package based statistical optimization of process components to simultaneously enhance the bacterial growth, laccase production and textile dye decolorization with cytotoxicity study. PLoS ONE 13(5): 0195795

Brillas E, Martínez-Huitle CA (2015) Decontamination of wastewaters containing synthetic organic dyes by electrochemical methods. An updated review. Appl Catal B Environ 166:603-643

Campos PA, Levin LN, Wirth SA (2016) Heterologous production, characterization and dye decolorization ability of a novel thermostable laccase isoenzyme from Trametes trogii BAFC 463. Process Biochem 51(7):895-903

Cavka A, Jönsson LJ (2014) Comparison of the growth of filamentous fungi and yeasts in lignocellulose-derived media. Biocatal Agric Biotechnol 3(4):197-204

Chung KT (2016) Azo dyes and human health: a review. J Environ Sci Health C Environ Carcinog Ecotoxicol Rev 34:233-261

Daâssi D, Zouari-Mechichi H, Frikha F, Rodríguez-Couto S, Nasri M, Mechichi T (2016) Sawdust waste as a low-cost supportsubstrate for laccases production and adsorbent for azo dyes decolorization. J Environ Health Sci Eng 14:1

de Souza Bezerra TM, Bassan JC, de Oliveira Santos VT, Ferraz A, Monti R (2015) Covalent immobilization of laccase in green coconut fiber and use in clarification of apple juice. Process Biochem 50:417-423

dos Santos AB, Cervantes FJ, van Lier JB (2007) Review paper on current technologies for decolourisation of textile wastewaters: perspectives for anaerobic biotechnology. Bioresour Technol 98:2369-2385

EC Commission Regulation (EC) No 552/2009 of 22 June 2009 Amending Regulation (EC) No 1907/2006 of the European Parliament and of the Council on the Registration, Evaluation, Authorisation and Restriction of Chemicals (REACH) as Regards Annex XVII (2009) http://eurlex.europa.eu/LexUriServ /LexUriServ.do?uri=OJ:L:2009:164:0007:0031:EN:PDF

Eggert C, Temp U, Dean JFD, Eriksson KEL (1996) A fungal metabolite mediates degradation of non-phenolic lignin structures and synthetic lignin by laccase. FEBS Lett 391:144-148
Fang Z, Liu X, Chen L, Shen Y, Zhang X, Fang W, Wang X, Bao X, Xiao Y (2015) Identification of a laccase Glac15 from Ganoderma lucidum 77002 and its application in bioethanol production. Biotechnol Biofuels 8:54

Guerrero-Coronilla I, Morales-Barrera L, Cristiani-Urbina E (2015) Kinetic, isotherm and thermodynamic studies of amaranth dye biosorption from aqueous solution onto water hyacinth leaves. J Environ Manag 152:99-108

Jasińska A, Różalska S, Bernat P, Paraszkiewicz K, Długoński J (2012) Malachite Green decolorization by non-basidiomycete filamentous fungi of Penicillium pinophilum and Myrothecium roridum. Int Biodeterior Biodegrad 73:33-40

Jasińska A, Bernat P, Paraszkiewicz K (2013) Malachite green removal from aqueous solution using the system rapeseed press cake and fungus Myrothecium roridum. Desalin Water Treat 51:7663-7671

Jasińska A, Góralczyk A, Długoński J (2016) Dyes decolourisation and degradation by microorganisms. In: Długoński J (ed) Microbial biodegradation: from omics to function and application. Caister Academic Press, Norflok, pp 119-141

Jasińska A, Góralczyk A, Soboń A, Długoński J (2018) Novel laccaselike multicopper oxidases from the Myrothecium roridum fungusproduction enhancement, identification and application in the dye removal process. Acta Biochim Pol 65(2):287-295

Jaszek M, Miłek J, Żuchowski J, Stefaniuk D, Prendecka M (2016) Effective and complex stimulation of the biodegradation system of fungus Cerrena unicolor by rapeseed meal fermentation. Acta Biochim Pol 63(3):549-554

Jung KW, Choi BH, Hwang MJ, Jeong TU, Ahn KH (2016) Fabrication of granular activated carbons derived from spent coffee grounds by entrapment in calcium alginate beads for adsorption of acid orange 7 and methylene blue. Bioresour Technol 219:185-195

Karagöz S, Tay T, Ucar S, Erdem M (2008) Activated carbons from waste biomass by sulfuric acid activation and their use on methylene blue adsorption. Bioresour Technol 99(14):6214-6222

Koschorreck K, Richter SM, Ene AB, Roduner E, Schmid RD, Urlacher VB (2008) Cloning and characterization of a new laccase from Bacillus licheniformis catalyzing dimerization of phenolic acids. Appl Microbiol Biot 79(2):217-224

Kuhar F, Castiglia V, Levin L (2015) Enhancement of laccase production and malachite green decolorization by co-culturing Ganoderma lucidum and Trametes versicolor in solid-state fermentation. Int Biodeterior Biodegrad 104:238-243

Liu Z, Zeng Z, Zeng G, Li J, Zhong H, Yuan X, Liu Y, Zhang J, Chen M, Liu Y, Xie G (2012a) Influence of rhamnolipids and triton X-100 on adsorption of phenol by Penicillium simplicissimum. Bioresour Technol 110:468-473

Liu ZF, Zeng GM, Zhong H, Yuan XZ, Fu HY, Zhou MF, Ma XL, Li $\mathrm{H}, \mathrm{Li}$ JB (2012b) Effect of dirhamnolipid on the removal of phenol catalyzed by laccase in aqueous solution. World J Microbiol Biotechnol 28:175-181

Mate DM, Alcalde M (2017) Laccase: a multi-purpose biocatalyst at the forefront of biotechnology. Microb Biotechnol 10(6):1457-1467

Miller GL (1959) Use of dinitrosalicylic acid reagent for determination of reducing sugars. Anal Chem 31:426-428 
Mpountoukas P, Pantazaki A, Kostareli E, Christodoulou P, Kareli D, Poliliou S, Mourelatos C, Lambropouloua V, Lialiarisa T (2010) Cytogenetic evaluation and DNA interaction studies of the food colorants amaranth, erythrosine and tartrazine. Food Chem Toxicol 48(10):2934-2944

Nguyen T, Saleh MA (2016) Detection of azo dyes and aromatic amines in women undergarment. J Environ Sci Health A 51:744-753

Osma JF, Toca-Herrera JL, Rodriguez-Couto S (2011) Cost analysis in laccase production. J Environ Manag 92(11):2907-2912

Qiao W, Chu J, Ding S, Song X, Yu L (2017) Characterization of a thermo-alkali-stable laccase from Bacillus subtilis cjp3 and its application in dyes decolorization. J Environ Sci Health A 52(8):710-717

Ronzon T, Lusser M, Klinkenberg M, Landa L, Sanchez Lopez J, M'Barek R, Hadjamu G, Belward A, Camia A, Giuntoli J, Cristobal J, Parisi C, Ferrari E, Marelli L, Torres de Matos C, Gomez Barbero M, Rodriguez Cerezo E (2017) Bioeconomy report 2016. In: Klinkenberg M, Sanchez Lopez J, Hadjamu G, Belward A, Camia A (eds) JRC scientific and policy report. EUR 28468 EN

Schalchli H, Hormazábal E, Rubilar O, Briceño G, Mutis A, Zocolo GJ, Diez MC (2017) Production of ligninolytic enzymes and some diffusible antifungal compounds by white-rot fungi using potato solid wastes as the sole nutrient source. J Appl Microbiol 123(4):886-895

Sen SK, Raut S, Bandyopadhyay P, Raut S (2016) Fungal decolouration and degradation of azo dyes: a review. Fungal Biol Rev 30:112-133
Silva JP, Sousa S, Rodrigues J, Antunes H, Porter JJ, Gonçalves IV, Ferreira-Dias S (2004) Adsorption of acid orange 7 dye in aqueous solutions by spent brewery grains. Sep Purif Technol 40(3):309-315

Singh RL, Singh PK, Singh RP (2015) Enzymatic decolorization and degradation of azo dyes - a review. Int Biodeterior Biodegrad 104:21-31

Singhaniaa RR, Patel AK, Soccol CR, Pandey A (2009) Recent advances in solid-state fermentation. Biochem Eng J 44(1):13-18

Singleton VL, Orthofer R, Lamuela-Raventós RM (1965) Analysis of total phenols and other oxidation substrates and antioxidants by means of Folin-Ciocalteu reagent. Methods Enzym 299:152-178

Songulashvili G, Spindler D, Jimenéz-Tobón GA, Jaspers C, Kerns G, Penninck MJ (2015) Production of a high level of laccase by submerged fermentation at 120-L scale of Cerrena unicolor C-139 grown on wheat bran. C R Biol 338(2):121-125

Szydłowska-Czerniak A, Łaszewska A (2015) Effect of refining process on antioxidant capacity, total phenolics and prooxidants contents in rapeseed oils. LWT Food Sci Technol 64:853-859

Vuorela S, Meyer AS, Heinonen M (2004) Impact of isolation method on the antioxidant activity of rapeseed meal phenolics. J Agric Food Chem 52(26):8202-8207

Wang F, Hu H, Guo C, Liu CZ (2014) Enhanced laccase production by Trametes versicolor using corn steep liquor as both nitrogen source and inducer. Bioresour Technol 166:602-605

Wang SS, Ning YJ, Wang SN, Zhang J, Zhang GQ, Chen QJ (2017) Purification, characterization, and cloning of an extracellular 
laccase with potent dye decolorizing ability from white rot fungus Cerrena unicolor GSM-01. Int J Biol Macromol 95:920-927

Yang M, Zheng C, Zhou Q, Liu C, Li W, Huang F (2014) Influence of microwaves treatment of rapeseed on phenolic compounds and canolol content. J Agric Food Chem 62(8):1956-1963

Yang J, Ng TB, Lin J, Ye X (2015) A novel laccase from basidiomycete Cerrena sp.: cloning, heterologous expression, and characterization. Int J Biol Macromol 77:344-349

Yaseen DA, Scholz M (2018) Textile dye wastewater characteristics and constituents of synthetic effluents: a critical review. Int J Environ Sci Technol. https://doi.org/10.1007/s13762-018-2130-z
Zhang G, Ma Y (2013) Mechanistic and conformational studies on the interaction of food dye amaranth with human serum albumin by multispectroscopic methods. Food Chem 136(2):442-449

Zhuo R, Yu H, Yuan P, Fan J, Chen L, Li Y, Ma F, Zhang F (2018) Heterologous expression and characterization of three laccases obtained from Pleurotus ostreatus HAUCC 162 for removal of environmental pollutants. J Hazard Mater 344:499-510

Zimbardi AL, Camargo PF, Carli S, Aquino Neto S, Meleiro LP, Rosa JC, de Andrade AR, Jorge JA, Furriel RP (2016) A high redox potential laccase from Pycnoporus sanguineus RP15: potential application for dye decolorization. Int J Mol Sci 17(5):672-996 